\title{
Entrevista com um "ph.d. nada típico": Xangô, Weber, Gilberto Freyre e outros assuntos com Roberto Motta
}

Interview with a "Non-Typical PH.D” Xango, Weber, Gilberto Freyre and other Subjects with Roberto Motta

\section{Realizada e apresentada por Amurabi Oliveira ${ }^{1}$}

Resumo: Roberto Motta é professor Titular aposentado da Universidade Federal de Pernambuco, atuante nos Programas de Pós-Graduação em Antropologia e em Sociologia. Foi professor visitante em várias instituições, principalmente

no e

1 Doutor em Sociologia pela Universidade Federal de Pernambuco (UFPE). Professor da Universidade Federal de Santa Catarina (UFSC) e do Programa de Pós-Graduação em Sociologia Política desta mesma Instituição. Contato: amurabi_cs@hotmail.com

Latitude, Vol. 8, no 2, pp. 427-440, 2014

DOI: https://doi.org/10.28998/2179-5428.20140208 


\section{Participação de mulheres no cenário eleitoral brasileiro: questões e explicações na ciência política} Women's participation in the Brazilian electoral scenario: questions and
explanations in political science

\section{Priscila Lapa ${ }^{1}$ \\ Jamerson Kemps ${ }^{2}$}

Resumo: Nas discussões sobre a presença feminina na esfera política são comuns argumentos que explicam a reduzida participação de mulheres em razão de condicionantes estruturais, demonstrando que nos padrões sociais estabelecidos estão localizados os determinantes causais desse fenômeno, de modo que a dominação dos homens sobre as mulheres no espaço privado se reproduziria no espaço público. Este artigo busca apontar como essa discussão está presente nas explicações acerca da eleição de mulheres no cenário político brasileiro, apresentando os principais argumentos utilizados à luz da Teoria Social. Apresenta também de que maneira a literatura acerca dos determinantes do voto na Ciência Política formula análises sobre a escolha de mulheres nas eleições brasileiras, levando em conta que os estudos contemporâneos amparam-se em diversos pressupostos do neoinstitucionalismo e da Teoria da Escolha Racional. Nessa perspectiva, este trabalho intenta apresentar novas perspectivas para se debater a eleição de mulheres que começam a surgir a partir das lacunas existentes nas análises tradicionais do fenômeno.

\footnotetext{
${ }^{1}$ Doutoranda em Ciência Política no Programa de Pós -Graduação em Ciência Política da Universidade Federal de Pernambuco. Jornalista, mestre em Ciência Política (UFPE, 2007). Área de concentração: Estudos eleitorais. E-mail: lapapriscila@gmail.com

2 Doutorando em Sociologia no Programa de Pós -Graduação em Sociologia da Universidade Federal de Pernambuco. Professor, licenciado em História e mestre em Antropologia, ambos pela UFPE.
} 
xterior, e é atualmente pesquisador Sênior do CNPq. Trabalha no campo de pesquisa das religiões afro-brasileiras, bem como na área de pensamento social, voltado principalmente para a análise das produções de Max Weber, Gilberto Freyre e Roger Bastide. Nesta entrevista, ele nos possibilita conhecer um pouco de sua trajetória intelectual, realizando uma análise bastante interessante de seu campo de investigação, que envolve tanto as religiões afro-brasileiras, quanto o pensamento social, destacando questões oportunas de serem problematizadas pela Antropologia e pela Sociologia brasileiras.

Palavras-Chave: Antropologia Brasileira; Religiões Afro-Brasileiras; Pensamento Social; Max Weber; Gilberto Freyre.

Abstract: Roberto Motta is Full Professor at the Federal University of Pernambuco, active in Postgraduate Programs of Anthropology and Sociology at this same university. He had been a visiting professor at various institutions especially abroad, and is a currently Senior Researcher of CNPq. His researches are around the field of african-brazilian religions as well as in the area of social thought, focused primarily on the analysis of the productions of Max Weber, Gilberto Freyre and Roger Bastide. In this interview he allows us to know a little bit of his intellectual trajectory, still carrying a very interesting analysis of his fields researches, involving african-Brazilian religions as social thought, highlighting quite timely issues being problematized by the Brazilian Anthropology and Sociology.

Keywords: Brazilian Anthropology; Afro-Brazilian Religions; Social Thought; Max Weber; Gilberto Freyre.

\section{Apresentação}

Roberto Motta nasceu no Recife, onde se graduou em Filosofia. Realizou posteriormente mestrado em Ciências Sociais pelo Instituto de Ciências Sociais de Haia, na Holanda, e doutorado em Antropologia pela Universidade de Colúmbia, nos Estados Unidos. Fez pós-doutorado nas universidades de Paris V, em Harvard e na Universidade da Califórnia, em Los Angeles. Foi pesquisador da Fundação Joaquim Nabuco e professor 
titular da Universidade Federal de Pernambuco, tendo sido um dos fundadores do Programa de Pós-Graduação em Antropologia desta Universidade em 1977, onde continua a lecionar e orientar trabalhos em nível de mestrado e doutorado. Tem também ministrado disciplinas e orientado teses na Pós-Graduação em Sociologia da mesma universidade. Foi ainda professor visitante nas universidades de Paris V, Lyon, Nice, Roma II, Caen, da Califórnia em Los Angeles, do Center for the Study of World Religions de Harvard, da Ecole des Hautes Etudes en Sciences Sociales, de Paris, sem esquecer a Universidade Estadual da Paraíba. Atualmente é pesquisador Senior do CNPQ e pesquisador associado do Groupe de Sociologie des Religions et de la Laicité do Centre National de la Recherche Scientifique (CNRS).

Seus interesses de pesquisa englobam os campos da Antropologia e da Sociologia da Religião, de Religiões Afro-brasileiras, Relações Raciais e Pensamento Social, com ênfase em Max Weber, Roger Bastide e Gilberto Freyre. Participa do comitê científico de inúmeros periódicos e possui vários artigos, livros, coletâneas e capítulos de livro publicados no Brasil e no exterior. Recentemente organizou as coletâneas "Gilberto Freyre: Região, Tradição, Trópico e outras aproximações" (2013), e “L'Actualité de Roger Bastide: Race, Religion, 'Saudade'"' (2005).

Amurabi Oliveira. Gostaria de iniciar a entrevista pedindo para que você nos relate um pouco de sua trajetória acadêmica, indicando como que se enveredou pelo campo da Antropologia.

Roberto Motta. Eu gosto de dizer que entrei na Antropologia um tanto por acaso. Quando eu saí do Recife para estudar na Universidade de Columbia na Cidade de Nova Iorque (este é o nome oficial) eu estava querendo entrar no Departamento de Sociologia. Eu já tinha ganho uma bolsa "Fulbright" para financiar meus estudos. E eu também já tinha feito os exames aos quais, nos Estados Unidos, era costume que se submetessem os que queriam fazer estudos pós-graduados. Eu me saí muito bem em alguns desses exames, porém, bem menos bem em tudo que exigisse raciocínio matemático. Nesta área eu sempre fui e sempre serei um perfeito débil mental. Não sei nem como foi que, aqui no Brasil, me deixaram terminar o curso secundário. Meu perfil intelectual se caracterizava por muitas letras e poucos números. Quando cheguei a Columbia, o Professor 
Charles Wagley, grande antropólogo e "Brazilianist", meu mentor nesses primeiros trâmites, sugeriu que eu me dirigisse ao Departamento de Antropologia, que exigia pouca ou nenhuma matemática, e não ao de Sociologia, que exigia muita. Fiquei um tanto frustrado. Eu tinha planos de escrever uma grande tese de inspiração weberiana, mas simplesmente não se falava em Weber no Departamento de Antropologia. A verdade é que também não sei se se falava muito em Weber no próprio Departamento de Sociologia de Columbia. Como quer que isto tenha acontecido, eu com mais 15 dias, já estava me sentindo felicíssimo na Antropologia. Charles Wagley, que já estava com aposentadoria marcada, transferiu o meu passe para o Professor Robert Murphy, que veio a ser um dos maiores amigos e benfeitores que tive em toda minha vida. Eu certamente me saí muito melhor em Antropologia do que teria sido o caso em Sociologia e não creio que tenha sido só questão de matemática. Mas nunca deixei de achar que a Antropologia e a Sociologia são fundamentalmente a mesma ciência, diferindo só em algumas ênfases de objeto e método.

A.O. Em O Antropólogo e sua Magia você é entrevistado por Vagner Silva acerca de seu percurso no campo das Religiões Afro-Brasileiras, onde toca em pontos interessantes como no fato de ter vivenciado uma verdadeira conversão psicológica, mas não intelectual no Xangô. Explorando um pouco mais esta questão, como emergiu esse interesse de pesquisa, e como avalia essas últimas quatro décadas dedicadas a este campo?

R.M. Foi Robert Murphy que me botou nesse mau caminho, ou nesse bom caminho. Eu a princípio relutei em segui-lo. Mas, a partir do momento em que comecei a fazer minha pesquisa de campo, o Xangô começou a crescer dentro de mim. Talvez eu pudesse dizer, em termos bourdieusianos, que adquiri o habitus do Xangô. Não vou querer fazer aqui uma digressão escolástica. Eu diria que eu já tinha adquirido esse habitus quando comecei a sonhar em termos de Xangô, orixás, sessões de adivinhação "y otras cositas más". Mas esse habitus vai mais longe. Espero que isto não pareça presunçoso, mas a partir de certo momento, eu me transformei num dos meus próprios informantes. Eu gerava a lógica daquela religião, como o falante de um idioma gera a cada momento a língua que está falando. De certo modo eu me tornei filho-de-santo. Meu 
caso, diga-se de passagem, está longe de ter sido único. Não creio que tenha sido o caso de Roger Bastide, mas foi, exponencialmente, o de Pierre Verger. Em Pernambuco foi também o de Maria do Carmo Brandão, cuja pesquisa e a minha estiveram inextrincavelmente associadas.

Claro que eu também me informava com filhos-de-santo, com colegas e, sobretudo, com a prática concreta, da qual fui cuidadoso observador. Eu penso que captei, nessa religião à qual jamais me converti, os aspectos mais práticos, como, por exemplo, a lógica (e as contradições) da redistribuição de alimentos e outros recursos através dos ritos sacrificiais. Essa importância prática era ainda muito forte já bem entrado o último quarto do século XX. Mas, em íntima mistura com os aspectos práticos, havia os sublimes. E nessa mistura se encontra a grandeza do Xangô. Penso em determinadas cerimônias nas quais o ser humano enfrenta sua precariedade, sua contingência, fragilidade e mortalidade. Ebori, amassi, transe e vai por aí.

Em minha família e nas minhas origens étnicas nada havia que se aproximasse do Xangô. Mas havia um "não sei o quê" de fundamental em minha experiência de menino recifense, nos anos 1940 e 1950, que eu fui redescobrir no Xangô. Digamos que, em toda a minha longa, profunda e participante experiência de campo, foi também a mim mesmo que descobri. É por isto que eu gosto tanto desta passagem de Aristóteles: “aquele que se encontra em ato de conhecer é idêntico ao próprio objeto em ato de ser conhecido".

A.O. E como você avalia o atual cenário das investigações sobre religiões afro-brasileiras?

R.M. As religiões afro-brasileiras têm sido estudadas com tal frequência, que já se observa nesse campo os efeitos da lei dos rendimentos decrescentes. Em artigo prestes a ser publicado numa revista da Bahia, eu falo no "Candomblé de Salão", entidade abstrata para ser utilizada em encontros científicos e trabalhos de afro-brasilianistas, dispensando totalmente o trabalho de campo. É um modelo essencialmente livresco, largamente baseado em Roger Bastide mal interpretado, mas também em Bastide mal interpretando, modelo que penetrou na doxa dos dicionários, dos manuais, da mídia e das pós-graduações. Notemos que, na Academia brasileira, tudo que seja diferente desse modelo é encarado como uma 
grave falta de etiqueta, uma inconveniência social. É por isto que o excelente livro, a verdadeira obra-prima de Seth e Ruth Leacock, sobre o Batuque de Belém, Spirits of the Deep, publicado em 1972, não foi até hoje publicado no Brasil. A religião afro-brasileira, semelhantemente a outras religiões (isto, antes de ser Elíade, é Freud), obedece à lei da incessante repetição. Os estudos sobre essa religião seguem a mesma lógica, ou antilógica.

A.O. Outro aspecto que se destaca em sua produção acadêmica diz respeito ao pensamento social, com uma especial atenção a Max Weber. Qual a atualidade desse clássico, e qual a capacidade heurística de sua obra para interpretar a realidade brasileira?

R.M. Não é fácil responder esta pergunta. Eu gostaria de dizer que a obra de Max Weber sobre a ética protestante tem para mim importância pessoal. Eu sou neto de um pastor presbiteriano, pai de minha mãe, e sobrinho de um bispo católico, irmão de meu pai. Minha família materna era profundamente americanizada e, em parte, emigrou para os Estados Unidos. Até hoje eu sou cheio de referências protestantes e anglo-saxônicas. $\mathrm{Eu}$, desde pequeno, como o menino egípcio de que Claude Lévi-Strauss fala em As Estruturas Elementares do Parentesco, sempre vivi num mundo dual. Quando eu penetro mais no lado protestante, minha parte católica começa a reclamar e me leva a me sentir culpado. E vice-versa. Isto pode parecer completamente estapafúrdio, mas é por mim mesmo que começa a crítica da Ética Protestante.

Mas eu estou me desviando de sua pergunta. A obra de Weber tem capacidade heurística para interpretar a realidade brasileira? Não sei se eu saberia responder. Mas sei que a obra de Weber tem sido utilizada para interpretar essa realidade. O exemplo clássico é o de Raízes do Brasil, de S. B. de Holanda, que eu hoje em dia tendo a considerar como um trabalho passavelmente superficial, talvez inferior a Bandeirantes e Pioneiros, de Viana Moog. O que se sabe menos é que certas teses de Weber foram antecipadas pelo alagoano Aureliano Tavares Bastos, em meados do século XIX. Este autor já tem sido estudado, mas precisa ser ainda mais. Até no vocabulário ele antecipa Weber. Mas não se trata de mais um caso para a Europa curvarse ante o Brasil. Esse vocabulário comum deriva certamente das Lições sobre a Filosofia da História, de Hegel, da qual Tavares Bastos deve ter 


\section{Entrevista com Roberto Motta}

tomado conhecimento através de autores franceses. A tese fundamental da passagem da Tradição à Racionalização estava em Hegel, antes de estar em Weber.

A.O. No artigo intitulado Reação a Max Weber no Pensamento Brasileiro: O Caso de Gilberto Freyre, você levanta uma hipótese interessante ao apontar para o caráter "anti-weberiano" de Freyre, poderia explicar um pouco mais sobre a ligação que você percebe entre esses dois pensadores?

R.M. Não devemos esquecer que Gilberto Freyre, seguindo seu mestre Charles Maurras, talvez o maior pensador da Direita francesa de todos os tempos, era acima de tudo um Tradicionalista. No sistema de Maurras, bem como no de Freyre, processos como a Racionalização e a Modernização, que nos sistemas de Hegel e Weber, encontram-se ligados à "autonomia do individuo" e à afirmação da subjetividade, possuíam importância muito secundária. Tanto Maurras como Freyre de vez em quando faziam o elogio do analfabetismo. Freyre talvez mais do que Maurras e já bem entrado o tempo do seu homônimo, e talvez parente, Paulo Freire. Isto não me impede de achar Gilberto um grande, imenso escritor e intérprete do Brasil. Como nota de pé de página possa eu dizer que, apesar do caráter essencialmente tradicionalista e, portanto, de certa maneira, conservador do seu pensamento, Gilberto teve flertes e namoros com o movimento comunista. Em certo texto ele elogia Stalin pela revalorização das tradições do povo russo... Penso que o rompimento definitivo de Gilberto com o movimento comunista ou, em geral, com a esquerda, ocorreu por volta de 1955. Foi por aí que recusou acintosamente um convite para visitar a China de Mao Tse Tung. Gilberto, em 1946, havia sido eleito Deputado Federal na chapa do movimento da "esquerda democrática", uma espécie de frente de expansão do movimento comunista. Quando não se reelegeu, em 1950, ficou sentido com o PCB e simpatizantes... Mas Gilberto certamente também percebeu a severidade dos Americanos com relações aos intelectuais que apoiassem, mesmo de leve, iniciativas comunistas. José Lins do Rego foi um dos prejudicados pela severidade americana.

Vou agora contar um episódio do qual pouca gente, ou nenhuma, tem conhecimento, fora eu. Como se diz, o diabo sabe das coisas não por ser diabo, mas por ser velho. E como dizia o poeta, "eu me lembro, eu me 
lembro, era pequeno, o mar bramia"... Enfim, eu me lembro, eu me lembro que, numa tarde de domingo do mês de maio de 1955, meu pai me levou para uma visita que ele ia fazer a Gilberto. Lá fui eu. Eu tinha 14 anos. Eu era um rapazinho um tanto serelepe, mas bom observador, até demais. $\mathrm{Na}$ casa de Gilberto estava também um jovem casal muito simpático, Clóvis e Claudomira Mello. Eles eram ligados ao PC. Clóvis era filho de Mário Mello, famoso jornalista e intelectual recifense, o qual era parente bastante próximo de Gilberto, cujo nome oficial era Gilberto de Mello Freyre. Ambos, Gilberto e Mário, eram alguma coisa como bisnetos ou trinetos de um Índio que, tendo se incorporado à cultura luso-tropical, havia recebido uma significativa data de terras na área de Escada, Mata Sul de Pernambuco. Gilberto, do que eu me lembre, fala desse antepassado apenas no livro de memórias, Dos Oito aos Oitenta e Tantos, cujo autor principal era o pai de Gilberto, Alfredo Freyre, muito embora essa ascendência fosse pelo lado de Dona Francisca, mãe de Gilberto.

Mário Mello era muito nativista. Para ele todas as cidades deviam ter nome tupi. E ele sempre dava um jeito de destacar a ascendência índia, o que não era do gosto de Gilberto. Por esta e por outras, sobrava pouca amizade entre os dois ilustres primos. Mário não sendo de forma alguma menos famoso no Recife dos anos 1950 do que Gilberto.

Mas eu acabei contando uma história dentro de outra. Recordando essa história, eu fico especulando se Clóvis não estava lá em missão política. O fato foi que, em dado momento, Clóvis trouxe à baila o nome de Juscelino Kubitschek, pré-candidato à presidência da República nas eleições daquele ano. Gilberto respondeu com entusiasmo. Disse que simpatizava muito com Juscelino, inclusive porque este era, segundo Gilberto, "mulato". Disse também que Juscelino, quando viesse ao Recife, haveria de hospedar-se em Apipucos, na casa da família Freyre. Tendo ouvido isso, muito surpreso fiquei eu quando, alguns meses ou semanas depois, Gilberto manifestou seu apoio ao adversário, derrotado, de Juscelino, Juarez Távora. Sobre a atitude de Gilberto há diversas especulações possíveis. O certo é que, naquele ano de 1955, a mudança de posição de Gilberto era mais uma etapa no rápido trânsito de Gilberto, passando de alguns graus à esquerda do centro para muitos graus à direita desse mesmo centro.

A.O. Freyre além de ser um objeto de investigação também foi uma 
pessoa com quem você conviveu, que chegou inclusive a escrever um artigo sobre sua pessoa ("Um Ph.D nada típico"2). Qual a impressão mais forte que ele lhe deixou como intelectual?

R.M. Eu fiquei muito constrangido quando esse artigo muito elogioso foi publicado em 1978. Gilberto também o leu acintosamente na sessão inaugural da reunião da $\mathrm{ABA}$, que se realizou no Recife em maio daquele ano. Eu ainda nem sequer tinha defendido minha tese e não deixou de haver os que me lembrassem de minha desconfortável situação, não de Ph.D. nada típico, mas de um muito típico "ABD", "all but the dissertation", isto é, tudo menos a tese. Os elogios, justos ou injustos, pérfidos ou generosos, me colocaram em posição difícil com relação aos colegas da ABA. Parecia que aquilo tinha sido mais um exemplo da perversidade pernambucana. Penso que ainda hoje não fui perdoado por esse artigo de Gilberto. E acredito que muita da hostilidade gerada por Gilberto veio a cair sobre René Ribeiro, extremamente mal tratado na sessão final daquela mesma reunião.

Continuo agora tentando responder às duas últimas perguntas. Gilberto possuía grande brilho intelectual. Florestan pensava em termos rigorosos de um sistema meio funcionalista e meio marxista. À base desses pressupostos, Florestan não podia entender relações raciais salvo como relações de classe social. Ele era uma espécie de mecanicista, que não entendia o princípio dialético da passagem da quantidade à qualidade. Florestan não poderia compreender um sistema como o de Mary Douglas, com ênfase sobre Pureza e Perigo, que é afim ao sistema de Gilberto. Para este, tais noções de pureza, perigo e contaminação jamais teriam tido, entre Lusos e Luso-Descendentes, a importância que talvez ainda tenham numa área como o Sul dos Estados Unidos. (Já estou eu aqui retornando a minha dualidade Protestante/Católico).

A.O. Explorando um pouco mais essa questão, em alguns trabalhos você realiza uma comparação entre a forma de Gilberto Freyre e de Florestan Fernandes produzirem conhecimento, e interpretarem as relações raciais no Brasil. Em sua opinião, quais são as características mais distintivas entre os dois, e como você analisa o legado de Freyre, de forma

${ }^{2}$ Disponível em <http://bvgf.fgf.org.br/> 
mais específica?

R.M. Eu sou autor de um texto publicado, tanto em inglês como em português, no ano 2000. Em português se chama Paradigmas de Interpretação das Relações Raciais no Brasil.

Nesse texto, que eu desconfio que é muito mais lido do que citado, eu distingo três paradigmas. $\mathrm{O}$ de Florestan, que não consegue ver relações de raça a não ser como relações de classe. O de Carlos Hasenbalg, que diz que a situação atual, de evidente desvantagem na qualidade de vida da população afro-descendente, é devida a mecanismos sutis ou invisíveis de discriminação. E o de Gilberto, que não se ocupa muito com a evidente desvantagem dos afrodescendentes. Gilberto jamais se ocupou, mesmo de longe, com problemas ligados ao Desenvolvimento, crescimento do PIB, industrialização e parecidos. Para ele não parecia ter sentido o princípio segundo o qual "ou nós nos industrializamos ou eles nos esmagam".

Ao contrário de Florestan, ele não reduz a questão racial à questão das classes sociais. O que Gilberto destaca é a interpenetração de raças e culturas no Brasil. E isto devido a certas particularidades da colonização portuguesa no Brasil. Essas particularidades ele explica ora como resultado do patriarcalismo luso-brasileiro, influenciado pelo Islamismo (e nisto é muito seguidor de Franz Boas), ora pelo "franciscanismo", ora pelo "tropicalismo", ora, simplesmente, pelo caráter nacional português ou, ainda, pelo "imagismo" oposto ao "biblicismo". Notemos que este último contraste carrega uma rejeição fundamental a Weber e à sua obra.

No paradigma de Hasenbalg deduz-se indevidamente que, se há desigualdade, há discriminação. Toda desigualdade resultaria de alguma discriminação, ainda que "sutil". Mas não basta formular o que no máximo seria uma hipótese muito geral. É preciso concretizar essa hipótese. É preciso apontar para os mecanismos concretos, em que tempo e em que lugar, por quais pessoas exercidos, que teriam sido capazes de deixar a população afro-descendente em tal situação de desvantagem. Esta sim, é inegável. Faz parte de nossa experiência quotidiana. Porém dizer que discriminação se exerce através de mecanismos tão sutis que são invisíveis, é como dizer que não existem. É o princípio básico enunciado por George Berkeley. Existir é ser percebido, direta ou indiretamente, próxima ou remotamente.

Eu ainda acho que, dos três paradigmas, o de Gilberto, apesar de 
alguns conceitos nebulosos, é o que apresenta menos contradições metodológicas. Todo esse debate está cheio de complicações de ordem política. Gilberto e os que, em alguns aspectos, mas aspectos fundamentais, defendem a validade do paradigma gilbertiano, ficam na contramão das correntes políticas que prevalecem, inclusive na Academia.

Eu ainda destacaria outra dificuldade, quase insuperável, para que a interpretação gilbertiana do Brasil, que não se baseia nos valores da modernidade, tais como expressos em Hegel e Weber, possa vir a ser aceita pelas correntes dominantes do pensamento social brasileiro ou brasilianista. De certo modo, quanto mais Gilberto estiver certo, tanto mais ele estará errado... Veja Carl Degler, em seu trabalho seminal, Nem Branco, Nem Preto. É seminal não só intelectualmente. Direta ou indiretamente, Degler se ocupa com os oceanos de sêmen indevidamente emitidos, segundo ele, no processo da formação social do Brasil. O povo parece que só pensava "naquilo". Mas isto, diz ele, era a "saída de emergência do mulato", que ele encarava como repugnante. Nada disso, ele acrescenta e lamenta, foi feito em nome "do que se conhece sob o nome de ética protestante".

E por aí podemos ver que estamos diante não apenas de um problema de Antropologia ou Sociologia, mas também de uma questão capital de Filosofia da História, que é onde terminam toda a Antropologia e toda a Sociologia dignas do nome. Quisesse Gilberto ou não, quer disto tivesse ou não consciência, sua verdadeira luta, seu Kulturkampf, se trava, o que para ele é muito honroso, com Hegel, Weber e companhia limitada.

A.O. A partir desse debate podemos desenvolver uma reflexão em torno das relações de poder na produção acadêmica, ou colocando em outros termos, da Geopolítica Acadêmica como tem nos chamado à atenção as professoras Roberta Campos e Mísia Reesink. Você como intelectual que desenvolveu uma brilhante trajetória acadêmica de projeção internacional, porém a partir de um programa que podemos chamar de "periférico" em termos nacionais (como já ouvi você dizer numa palestra), como analisa essas relações no campo da Antropologia Brasileira atualmente?

R.M. O programa que eu ajudei a fundar ainda é um programa periférico. Será que eu desenvolvi uma "brilhante trajetória acadêmica de projeção internacional"? Eu não deixo de ter, em vários lugares fora do 
Brasil, pessoas que me apreciam. Mas não convém, nem de longe, exagerar. Eu muitas vezes acho que se espera de mim certa dose de exotismo. Eu me exprimo bem em francês, inglês, italiano, posso ao menos ler em alemão e fico por aqui.

Eu não sou nenhum galego, sou moreno quase jambo. Um senhor bem educado, que fala em tom literário, fazendo uns versinhos que surgem, sem ninguém desconfiar. "Convide pra sua festa, que ele é muito engraçado."

Mas eu nunca me esqueço do que uma vez ouvi de um grande amigo francês. Ele disse o seguinte: "Robertô, quando tu vens falar de Candomblé, as pessoas te escutam. Mas quando tu vens falar de Weber, $\mathrm{hm}, \mathrm{hm}$ ". Como se Weber não fosse coisa para brasileiro... Já falamos em hegemonias intelectuais... Estas não existem só no Brasil. O campo dos estudos weberianos tem os seus proprietários, na França não menos do que na Alemanha. Outsiders querendo impor-se por direito próprio, "are not welcome".

Eu já dei a entender que se Freyre rejeitava as ideias de Weber, mesmo que ele nem sempre se apercebesse do que queria, era essencialmente para afirmar a sua interpretação do Brasil. Na França, aceitar o paradigma weberiano da ética protestante era e é visto, em muitos círculos de cientistas sociais, como condição para a plena adesão da França à modernidade. Isto é um paradoxo porque, em muitos aspectos, a França liderou o Ocidente. Muitos franceses achavam e acham que, tendo o País resistido à Reforma, e sendo a Modernidade (Hegel, Weber...) protestante, a adesão ao paradigma weberiano seria uma maneira de compensar por aquela falha histórica. Isto também acontece no Brasil. É o caso de S. B. de Holanda.

Mas eu temo ter feito uma digressão que tem pouco a ver com a pergunta. Qualquer que seja minha repercussão internacional, estou certo de que não se fez a partir do nosso Programa em Antropologia, aqui da UFPE... Se eu fosse esperar por ele, eu viajaria muito pouco. Entre 1973, quando retornei do meu período de residência em Columbia, em 1982, eu não saí do Brasil nem uma só vez, nem me convidaram para nada. Depois veio meu encontro com Jean Duvignaud, Michel Maffesoli, minha amizade com Marion Aubrée, que considero uma das minhas grandes benfeitoras. Françoise Champion e Frédéric Alexandre. Minha entrada no Groupe de Sociologie des Religions et de la Laïcité, meu curso na École Pratique des Hautes 
Études, a convite de Jean-Paul Willaime. Cursos na Sorbonne, em Lyon, em Caen. Convites de Claude Rivière, Philippe Laburthe-Tolra, François Laplantine, Erwan Diateill, Claude Ravelet. Na Itália, M. I. Macioti, Roberto Cipriani, Federico d'Agostino, Gilberto Mazzoleni, Enzo Pace, Giuseppe Giordan. Nos Estados Unidos, Larry Lauerhass Jr. Ai, quantas saudades que eu tenho do que os anos não trazem mais... Meu período de "glória" foram os últimos anos do século XX e os primeiros do XXI. Nisto tudo minha condição de antropólogo ou de sociólogo desempenhou papel secundário, embora eu sempre "lattisse" meus créditos na Antropologia, para que essas coisas pudessem beneficiar minha pós-graduação.

Eu não entrei na Antropologia pela porta aberta no Brasil por David Maybury-Lewis e Roberto Cardoso de Oliveira, mas pela janela da Fundação Fulbright, da qual recebi uma bolsa depois de me submeter a concurso público, no qual minhas excelentes notas em inglês compensaram as péssimas em matemática. Meus mestres em Antropologia, Charles Wagley, Robert Murphy, Marvin Harris (apesar de divergências), Seth Leacock, que não foi meu professor mas que influenciou profundamente meu trabalho, eram gente mal vista pelo paradigma de Maybury-Lewis. Até se suspeitava que fossem comunistas... E eu era suspeito de uma incorreção em nada inferior: eu era gilbertofreyriano... De modo que meus contatos não se fizeram pelo Museu Nacional nem pela USP, mas diretamente com o exterior. Mas não tenho motivo para queixa. Desde cerca de 1985, tenho sido ininterruptamente bolsista em produtividade do CNPq, atualmente bolsa "senior", também chamada "pé-na-cova". Quem primeiro me colocou nesse circuito foi Klaas Wortmann, ao qual quero agora agradecer.

Vou concluir. Adaptando uma famosa passagem de São Leão, eu diria o seguinte. Antropólogo pernambucano, antropóloga pernambucana, reconhece a tua dignidade! ${ }^{3}$ Por que ficaríamos nós a receber o repasse das citações de Fulano, Sicrano ou de Beltrano? Nossos orientandos muitas vezes nos esnobam de uma ponta a outra de suas teses ou dissertações. Quando eu não tenho raiva eu acho graça, ou tenho as duas reações ao mesmo tempo. E, se lhe convier, meu caríssimo Amurabi, vou terminar com um poema-manifesto:

${ }^{3}$ Com isto eu não quero dizer que os sociólogos já tenham inteiramente perdido a deles. 


\begin{abstract}
Meu País
Manifesto localista

Muito tradicionalista.

Eu neste texto me sirvo,

Como em tudo mais que fiz,

Velho, novo, escrevivendo,

(Com licença de Jomard)

Palavra, forma, sintaxe,

Da língua de Pernambuco.

Uma légua rodeando o

Náutico, que é meu time.

E o Country, que eu herdei de

Um bisavô,que era inglês,

Por parte de Joana, a Louca?

(Esta a Bandeira não dou.)

Pela Estrada dos Aflitos,

Atravesso a minha terra.
\end{abstract}

"Blessed be the man that spares my words,

And cursed be he that moves my lines."

Referências:

DEGLER, Carl N. Nem branco nem preto: escravidão e relações raciais no Brasil e nos Estados Unidos. Rio de Janeiro: Labor do Brasil, 1976 [1971].

FREYRE, Alfredo. Dos oito aos oitenta e tantos. Recife, Editora da Universidade Federal de Pernambuco [prefácio de Gilberto Freyre], 1970.

HOLANDA, Sérgio Buarque. Raízes do Brasil. São Paulo: Companhia das Letras,

1963

[1936].

${ }^{4}$ Obras diretamente citadas na entrevista.

Latitude, Vol. 8, nº 2, pp. 427-440, 2014 


\section{Entrevista com Roberto Motta}

LEVI-STRAUSS, Claude. As estruturas elementares do parentesco. Tradução de Mariano Ferreira. Ed. Petrópolis, Vozes, 2009 [1908].

MOOG, Vianna. Bandeirantes e pioneiros. Paralelo entre duas culturas. Porto Alegre: Globo, 1961.

MOTTA, Roberto. "Reação a Max Weber no Pensamento Brasileiro: O Caso de Gilberto Freyre". Estudos de Sociologia. v. 13, p. 185-206, 2008.

- "Paradigmas de Interpretação das Relações Raciais no Brasil". Estudos Afro-Asiáticos, v. 38, p. 113-134, 2000.

SILVA, Vagner Gonçalves da. O antropólogo e sua magia. Trabalho de campo e texto etnográfico nas pesquisas antropológicas sobre as religiões afrobrasileiras. São Paulo: EDUSP, 2006.

Enviado em

03.10.2014

Aceito em

06.11.2014 